ORIGINAL ARTICLE

\title{
Prevalence and Trends of Major Transfusion Transmissible Infections among Blood Donors in Dire Dawa Blood bank, Eastern Ethiopia: Retrospective Study
}

\author{
Zerihun Ataro $^{1 *}$, Fekadu Urgessa ${ }^{2}$, Tagesachew Wasihun ${ }^{3}$
}

\section{OPEN ACCESS}

Citation: Zerihun Ataro, Fekadu Urgessa, Tagesachew Wasihun. Prevalence and Trends of Major Transfusion Transmissible Infections among Blood Donors in Dire Dawa Blood bank, Eastern Ethiopia: Retrospective Study from July 2010 to June 2013. Ethiop J Sci.2018;28(6):701.

doi:http://dx. doi.org/10.4314/ejhs.v28i6.4 Received: April 13, 2018

Accepted: July 4, 2018

Published: November 1, 2018

Copyright: (C) 2018 Zerihun Ataro, et al. This is an open access article distributed under the terms of the Creative Commons Attribution License, which permits unrestricted use, distribution, and reproduction in any medium, provided the original author and source are credited. Funding: Nil

Competing Interests: The authors declare that this manuscript was approved by all authors in its form and that no competing interest exists.

Affiliation and Correspondence:

${ }^{1}$ Department of Medical Laboratory Sciences, College of Health and Medical Sciences, Haramaya University, Harar, Ethiopia

${ }^{2}$ School of Medical Laboratory Sciences, College of Health Sciences, Addis Ababa University, Addis Ababa, Ethiopia

*Email: zerihunataro@yahoo.com

\begin{abstract}
BACKGROUND: Acquisition of transfusion transmissible infections in the process of therapeutic blood transfusion is a major global health challenge in transfusion medicine. This study aimed to determine the prevalence and trends of major transfusion transmissible infections among blood donors.

METHOD: A retrospective analysis of consecutive blood donors' records covering the period between July 2010 and June 2013 was conducted at Dire Dawa Blood Bank, Eastern Ethiopia.

RESULT: A total of 6376 blood donors were tested, out of which $5647(88.57 \%)$ were replacement donors and 729(11.43\%) were voluntary donors. The majority of them were male, 5430(85.16\%), and aged between 18-32 years, 4492(70.45\%). A total of 450(7.06\%) donors had serological evidence of infection with at least one pathogen. The overall positivity rates of $\mathrm{HBV}, \mathrm{HIV}, \mathrm{HCV}$ and syphilis were $4.67 \%, 1.24 \%, 0.96 \%$, and $0.44 \%$ respectively. Trends for transfusion-transmissible infections showed a significant decrease from $9.51 \%$ in 2010 to $6.95 \%$ in 2013 with the least prevalence in $2012(5.90 \%)(P=0.004)$. The prevalence of transfusion transmissible infections was significantly higher among male blood donors compared to female donors, among the age group of 25-32 years and 33-40 years compared to the age group of 18-24 years old, and among unemployed and private workers compared to students.

CONCLUSION: A significant percentage of the blood donors harbor transfusion-transmissible infections. Stringent donor selection using standard methods is highly recommended to ensure the safety of blood for the recipient. Furthermore, efforts on motivating and creating awareness in the community are required to increase voluntary blood donors.

KEYWORDS: Transfusion transmissible infections, prevalence, Trend, Ethiopia
\end{abstract}




\section{INTRODUCTION}

The presence of blood borne infections in blood cells or plasma of asymptomatic donors is the major risk factors for transmitting infectious agents through blood transfusion. Although blood transfusion service is mandatory to save the life of many patients who suffer from the loss of blood, it is an ideal vehicle for transmission of any infectious organism that may present in the blood (1). Common infectious agents include hepatitis B virus (HBV), hepatitis $\mathrm{C}$ virus (HCV), human immunodeficiency virus (HIV) and syphilis (2,3).

Unsafe blood transfusion is very costly from both human and economic points of view. Transfusion transmissible infectious diseases carry long term consequences for the recipients, families and the communities since the infected person represents a pool for the infection and can transmit the disease during its asymptomatic period. Therefore, transfusions can contribute to an ever widening pool of infection in the population $(4,5)$.

In developing countries, blood safety continues to be a major problem due to the high prevalence of infectious markers among blood donors (5). In sub-Saharan African countries, factors contributing to transfusion-related transmissions include a high prevalence of HIV and other transfusion transmitted infections in the general and blood donor populations; inadequate screening facilities; and lack of infrastructure and capacity to ensure sustainable operations (2). Sexually transmitted infections are also widespread in developing countries and constitute a major public health problem $(6,7)$. Syphilis has acquired a new potential for morbidity and mortality through association with increased risk of HIV infection, thus making more difficult to get safe blood (8). Ethiopia, being part of developing countries, has a high prevalence of HIV, HBV and other infectious diseases (9).

The prevalence of transfusion transmissible infections (TTIs) can reveal the problem of unnoticeable infections in healthy-looking members of the general population and also provide data that is important in formulating the strategies for improving the management of a safe blood supply. Although there are available data on the prevalence of these diseases in a general population and its high-risk population has been addressed (10-12), there are limited epidemiological data on TTIs on blood donors in Ethiopia $(13,14)$, especially in the eastern areas of Ethiopia. Therefore, this study was conducted to determine the prevalence and trends of major TTIs among blood donors at Dire Dawa Blood Bank in Eastern Ethiopia.

\section{MATERIALS AND METHODS}

We conducted a retrospective analysis of blood donor data recorded between December 2011 and May 2012 at Dire Dawa blood bank which is located $515 \mathrm{Km}$ East from the capital city, Addis Ababa. Dire Dawa blood bank is a regional blood bank established in 1988. According to the 2007 population census conducted by the Central Statistical Agency of Ethiopia (CSA), Dire Dawa had an estimated total population of 341,834 (15). There are four hospitals (one governmental and three private) and 15 health centers in the administration. The blood bank collects blood centrally and distributes blood for transfusion medicine to Dilchora hospital, the hospital serving as a referral hospital in the administration, and to other general hospitals and health institutions found in Dire Dawa administration.

The study population consisted of apparently healthy voluntary and replacement donors who presented for blood donation at the blood bank in the past three years. Voluntary donors are motivated blood donors who donate blood at regular intervals while replacement donors are usually one time blood donors who donate blood only when a relative or a friend is in need of blood.

During the first step of the screening process, individuals are required to give answers to a panel of questions about previous illnesses and medical conditions. Apparently healthy subjects of age 18 to 65 years with body weight above $45 \mathrm{~kg}$ would qualify for donation. The socio-demographic histories of the donors were recorded in the logbook, and venous blood was collected. All blood donors with complete records of their

DOI: http://dx.doi.org/10.4314/ejhs.v28i6.4 
socio-demographic and clinical data were included in the study. Donors with incomplete record were excluded from the study.

Donor's blood was screened for TTIs after donation. The blood samples were tested for anti$\mathrm{HIV}, \mathrm{HBsAg}$ and anti-HCV, and anti-syphilis antibody with standard enzyme-linked immunosorbent assay (ELISA) test kits. The hepatitis B surface antigen (HBsAg) was detected using Hepanostika HBsAg Ultra (Biomérieux, Boxtel, Netherlands), and the kit had a sensitivity of $100 \%$ and specificity of $99.9 \%$. Antibodies to HCV were detected using Hepanostika HCV Ultra (Beijing United Biomedical Co. Ltd., Beijing, China) which had a sensitivity of $100 \%$ and specificity of $99.7 \%$. Antibodies to HIV types 1 and 2 were screened using Vironostika HIV UniForm II $\mathrm{Ag} / \mathrm{Ab}$ (Biomérieux, Boxtel, Netherlands). The kit had a sensitivity of $100 \%$ and specificity of $99.7 \%$. Antibody for treponema pallidum was tested using rapid plasma reagin test (RPR, Wampole Laboratories, Princeton, N.J., USA) which had a sensitivity of $100 \%$.

All data were entered into Microsoft Excel spreadsheets and analyzed using STATA software version 13 (STATA Corp. College Station, Texas, USA). The seroprevalence of HIV, HCV, HBsAg and syphilis was expressed in percentages for the entire study group and by age, sex and donor category and comparisons between the groups were done using Pearson Chi-Square. Logistic regression was used to determine the associations between the occurrence of TTIs and selected variables. The associations are presented as odds ratio (OR) together with $95 \%$ confidence intervals (CI). P-value less than 0.05 was considered statistically significant.

The study proposal was approved by the Institutional Research and Ethics Review Committee of the College of Health and Medical Sciences, Haramaya University. With regard to confidentiality, no names were involved in the data analysis process; only codes were used to identify donors.

\section{RESULTS}

Characteristics of the blood donors: A total of 6376 blood donors were screened at Dire Dawa Blood Bank Unit from July 2010 to June 2013. Among them, 5430(85.16\%) were males. The median age of the study subjects was 27 (ranging from $18-65)$, and $2437(38.22 \%$ ) were in the age group of $18-24$ years old. Then, $5647(88.57 \%)$ were replacement donor while $729(11.43 \%)$ were volunteers. Of all donors, 3184(49.94\%) were blood group $\mathrm{O}$ and $6128(96.11 \%)$ were Rhesus positive. The majority of the blood donors were students, $1781(27.93 \%)$, followed by private workers, $1439(22.57 \%)$. Of the volunteer donors, $408(55.97 \%)$ were students, and there were $1,373(24.31 \%)$ students for replacement donors.

Prevalence of transfusion-transmissible infections (TTIs): Among the 6376 blood donors, 450 were confirmed positive for at least one pathogen, giving a prevalence of TTIs $7.06 \%$ (95\% CI 6.45-7.71\%). The overall positivity rates of HBV, HIV, HCV and syphilis were $4.67 \%$ (95\% CI $4.18-5.22 \%), 1.24 \%$ (95\% CI 0.99 $1.54 \%$ ), $0.96 \%$ (95\% CI $0.75-0.12 \%$ ) and $0.44 \%$ (95\% CI $0.30-0.64 \%)$ respectively. In addition, $16 / 6,080(0.25 \%)$ donors showed dual infections; of which the most common combinations were HBV-HCV, $8(50.00 \%)$, and HIV-HBV, $5(31.25 \%)$.

Trends of HBV, HIV, HCV and Syphilis infections: The trend for TTIs showed a significant decrease from $9.51 \%$ in 2010 to $6.95 \%$ in 2013 with the least prevalence in 2012(5.90\%) $(\mathrm{P}=0.004)$. Significantly decreasing trends of HBV prevalence were observed from 2010 to 2012 and then increased in $2013(\mathrm{P}<0.001)$. HCV infection trend shows an increment from $0.35 \%$ to $1.46 \%$, from 2010 to 2012 but slightly declined to $0.7 \%$ in 2013 . The prevalence of syphilis significantly decreased progressively throughout the period from $1.64 \%$ in $2010,0.47 \%$ in 2011 , $0.20 \%$ in 2012 and $0 \%$ in 2013. The prevalence of HIV varied slightly among the years with no statistical significance $(P=0.602)$. Overall, HBsAg was the most prevalent pathogen (Table $1)$. 
Table 1: Trends of HBV, HIV, HCV and Syphilis infections among Blood Donors at Dire Dawa Blood Bank in Eastern Ethiopia, July 2010 - June 2013.

\begin{tabular}{lclllll}
\hline Year & $\begin{array}{c}\text { Total } \\
\mathbf{N}\end{array}$ & $\begin{array}{c}\text { HBV positive } \\
\mathbf{N}(\%)\end{array}$ & $\begin{array}{l}\text { HIV positive } \\
\mathbf{N}(\%)\end{array}$ & $\begin{array}{l}\text { HCV positive } \\
\mathbf{N}(\%)\end{array}$ & $\begin{array}{l}\text { Syphilis positive } \\
\mathbf{N}(\%)\end{array}$ & $\begin{array}{l}\text { Total TTIs } \\
\mathbf{N}(\%)\end{array}$ \\
\hline 2010 & 852 & $56(6.57)$ & $9(1.06)$ & $3(0.35)$ & $14(1.64)$ & $81(9.51)$ \\
2011 & 1914 & $98(5.12)$ & $29(1.52)$ & $14(0.73)$ & $9(0.47)$ & $144(7.52)$ \\
2012 & 2459 & $83(3.38)$ & $29(1.18)$ & $36(1.46)$ & $5(0.20)$ & $145(5.90)$ \\
2013 & 1151 & $61(5.30)$ & $12(1.04)$ & $8(0.70)$ & $0(0)$ & $80(6.95)$ \\
Total & 6376 & $298(4.67)$ & $79(1.24)$ & $61(0.96)$ & $28(0.44)$ & $450(7.06)$ \\
P-Value & $<0.0001$ & 0.602 & 0.008 & $<0.0001$ & 0.004 \\
\hline
\end{tabular}

$\mathrm{N}=$ number; TTIs $=$ Transfusion Transmissible Infections

Transfusion-transmissible infection (TTI) positivity rate by demographic characteristics: The prevalence of TTIs was significantly higher for male donors $(7.46 \%)$ than for female donors $(4.76 \%) \quad(\mathrm{P}=0.003)$. HBV infections were significantly more prevalent among males than female donors $(\mathrm{P}<0.001)$. Similarly, HCV, HIV and syphilis infections were more prevalent among the males, but none of the differences were significant $(\mathrm{P}>0.05)$. The prevalence of TTIs increased with age. Donors with age group 18-24 (5.87\%) showed a low prevalence of TTI. Similarly, HIV infection was less prevalent among donors with age group 18-24(0.57\%) (Table 2).

Table 2: Positivity rate of transfusion-transmissible infections by demographic characteristics and donation type at Dire Dawa Blood Bank in Eastern Ethiopia, July 2010 - June 2013.

\begin{tabular}{|c|c|c|c|c|c|c|c|}
\hline \multicolumn{2}{|c|}{ Characteristics } & \multirow{2}{*}{$\begin{array}{c}\begin{array}{c}\text { Total } \\
\mathbf{N}\end{array} \\
5430\end{array}$} & \multirow{2}{*}{$\begin{array}{l}\text { TTIs } \\
\text { N (\%) } \\
405(7.46)\end{array}$} & \multirow{2}{*}{$\begin{array}{l}\text { HBV } \\
\text { N (\%) } \\
275(5.06)\end{array}$} & \multirow{2}{*}{$\begin{array}{l}\text { HIV } \\
\text { N (\%) } \\
65(1.20)\end{array}$} & \multirow{2}{*}{$\begin{array}{l}\text { HCV } \\
\text { N (\%) } \\
56(1.03)\end{array}$} & \multirow{2}{*}{$\begin{array}{l}\begin{array}{l}\text { Syphilis } \\
\text { N (\%) }\end{array} \\
25(0.46)\end{array}$} \\
\hline Sex & Male & & & & & & \\
\hline & Female & 946 & $45(4.76)$ & $23(2.43)$ & $14(1.48)$ & $5(0.53)$ & $3(0.32)$ \\
\hline & P-value & & 0.003 & $<0.001$ & 0.468 & 0.143 & 0.539 \\
\hline \multirow{5}{*}{ Age group } & $18-24$ & 2437 & $143(5.87)$ & $102(4.19)$ & $14(0.57)$ & $20(0.82)$ & $8(0.33)$ \\
\hline & $25-32$ & 2055 & $159(7.74)$ & $106(5.16)$ & $27(1.31)$ & $21(1.02)$ & $13(0.63)$ \\
\hline & $33-40$ & 1083 & $88(8.13)$ & $53(4.89)$ & $22(2.03)$ & $13(1.20)$ & $5(0.46)$ \\
\hline & $\geq 41$ & 801 & $60(7.49)$ & $37(4.62)$ & $16(2.00)$ & $7(0.87)$ & $2(0.25)$ \\
\hline & $\overline{\mathrm{P}}$-value & & 0.032 & 0.474 & $<0.001$ & 0.728 & 0.374 \\
\hline \multirow{10}{*}{ Occupation } & Student & 1781 & $128(7.19)$ & $100(5.61)$ & $10(0.56)$ & $12(0.67)$ & $6(0.34)$ \\
\hline & Private worker & 1439 & $108(7.51)$ & $64(4.45)$ & $28(1.95)$ & $19(1.32)$ & $4(0.28)$ \\
\hline & Unemployed & 810 & $78(9.63)$ & $55(6.79)$ & $13(1.60)$ & $7(0.86)$ & $4(0.49)$ \\
\hline & Civil servant & 693 & $41(5.92)$ & $21(3.03)$ & $13(1.88)$ & $6(0.87)$ & $1(0.14)$ \\
\hline & Farmer & 490 & $31(6.33)$ & $18(3.67)$ & $3(0.61)$ & $8(1.63)$ & $6(1.22)$ \\
\hline & Driver & 361 & $27(7.48)$ & $20(5.54)$ & $5(1.39)$ & $3(0.83)$ & $2(0.55)$ \\
\hline & Private employee & 309 & $8(2.59)$ & $7(2.27)$ & $0(0.0)$ & $0(0)$ & $1(0.32)$ \\
\hline & Daily laborer & 155 & $8(5.16)$ & $3(1.94)$ & $3(1.94)$ & $3(1.94)$ & $0(0)$ \\
\hline & House wife & 134 & $10(7.46)$ & $5(3.73)$ & $4(2.99)$ & $0(0)$ & $1(0.75)$ \\
\hline & P-value & & 0.010 & 0.001 & 0.001 & 0.187 & 0.072 \\
\hline Donation & Replacement & 5647 & $410(7.26)$ & 265(4.69) & $77(1.36)$ & $57(1.01)$ & $27(0.48)$ \\
\hline \multirow{2}{*}{ type } & Volunteer & 729 & $40(5.49)$ & $33(4.53)$ & $2(0.27)$ & $4(0.55)$ & $1(0.14)$ \\
\hline & P-value & & 0.078 & 0.842 & 0.012 & 0.229 & 0.190 \\
\hline
\end{tabular}

$\mathrm{N}=$ Number; TTIs=Transfusion Transmissible Infections 
The TTIs prevalence also showed significant differences among different types of occupation $(\mathrm{P}=0.010)$. Unemployed donors showed the highest prevalence $(9.63 \%)$ of TTIs followed by private workers $(7.51 \%)$ and drivers $(7.48 \%)$. The prevalence of TTIs was $7.26 \%$ for replacement and $5.49 \%$ for volunteer donors, without significant difference $(\mathrm{P}>0.05)$. Among the four TTIs, HIV infection was more prevalent in replacement donors $(1.36 \%)$ than in volunteer donors $(0.27 \%)(\mathrm{P}=0.012)$ (Table 2$)$.
Multivariate analysis showed that, over all, the prevalence of TTIs was significantly higher among male blood donors $(\mathrm{p}=0.003)$ compared to female donors. It was significantly higher among the age group 25-32 years $(\mathrm{p}=0.013)$ and $33-40$ years $(\mathrm{p}=0.013)$ compared to age group $18-24$ years old. It was also significantly higher among unemployed $(\mathrm{P}=0.034)$ and private workers $(\mathrm{p}=0.004)$ compared to students (Table 3$)$.

Table 3: Multivariate analysis of the associations between transfusion-transmissible infections and demographic characteristics of the blood donors at Dire Dawa Blood Bank in Eastern Ethiopia, July 2010 June 2013

\begin{tabular}{|c|c|c|c|c|c|c|}
\hline \multirow[t]{2}{*}{ Characteristics } & \multirow[t]{2}{*}{ Total } & \multicolumn{5}{|c|}{ Positive for any TTIs } \\
\hline & & $\mathbf{N}(\%)$ & COR (95\%CI) & P-value & AOR (95\%CI) & P-value \\
\hline \multicolumn{7}{|l|}{ Sex } \\
\hline Female & 946 & $45(4.76)$ & 1.00 & & 1.00 & \\
\hline Male & 5430 & $405(7.46)$ & $1.61(1.18-2.21)$ & 0.003 & $1.68(1.17-2.40)$ & 0.005 \\
\hline \multicolumn{7}{|l|}{ Age group } \\
\hline $18-24$ & 2437 & $143(5.87)$ & 1.00 & & 1.00 & \\
\hline $25-32$ & 2055 & $159(7.74)$ & $1.35(1.06-1.69)$ & 0.013 & $1.65(1.24-2.19)$ & 0.001 \\
\hline $33-40$ & 1083 & $88(8.13)$ & $1.42(1.08-1.87)$ & 0.013 & $1.77(1.26-2.49)$ & 0.001 \\
\hline$\geq 41$ & 801 & $60(7.49)$ & $1.29(0.95-1.78)$ & 0.101 & $1.59(1.09-2.31)$ & 0.015 \\
\hline \multicolumn{7}{|l|}{ Occupation } \\
\hline Student & 1781 & $128(7.19)$ & 1.00 & & 1.00 & \\
\hline Private worker & 1439 & $110(7.51)$ & $1.05(0.80-1.37)$ & 0.730 & $0.68(0.49-0.95)$ & 0.023 \\
\hline Unemployed & 810 & $78(9.63)$ & $1.38(1.02-1.84)$ & 0.034 & $0.96(0.68-1.36)$ & 0.833 \\
\hline Civil servant & 693 & $41(5.92)$ & $0.81(0.56-1.17)$ & 0.261 & $0.55(0.36-0.83)$ & 0.004 \\
\hline Farmer & 490 & $31(6.33)$ & $0.87(0.58-1.31)$ & 0.509 & $0.54(0.34-0.86)$ & 0.009 \\
\hline Driver & 361 & $27(7.48)$ & $1.04(0.68-1.61)$ & 0.845 & $0.69(0.43-1.09)$ & 0.114 \\
\hline Private employee & 309 & $8(2.59)$ & $0.34(0.17-0.71)$ & 0.004 & $0.24(0.11-0.51)$ & 0.000 \\
\hline Daily laborer & 155 & $8(5.16)$ & $0.70(0.34-1.46)$ & 0.346 & $0.45(0.21-0.97)$ & 0.041 \\
\hline House wife & 134 & $10(7.46)$ & $1.04(0.53-2.03)$ & 0.905 & $1.08(0.50-2.33)$ & 0.847 \\
\hline \multicolumn{7}{|l|}{ Donation type } \\
\hline Replacement & 5647 & $410(7.26)$ & $1.35(0.97-1.88)$ & 0.080 & $1.12(0.79-1.61)$ & 0.512 \\
\hline Volunteer & 729 & $40(5.49)$ & 1.00 & & 1.00 & \\
\hline
\end{tabular}

$\mathrm{AOR}=$ Adjusted odds ratio; $\mathrm{COR}=$ Crude odds ration; $\mathrm{CI}=$ Confidence interval; $\mathrm{N}=$ Number; TTIs=Transfusion Transmissible Infections

\section{DISCUSSION}

In this study, most of the blood donors were males, 5430(85.16\%), aged between 18-32 years $(70.45 \%)$ and were mainly replacement, $5647(88.57 \%)$, rather than voluntary donors
$729(11.43 \%)$. This is consistent with observations in several other studies in Africa (14,16-18).

The World Health Organization (WHO) recommends collection of blood from voluntary regular non-remunerated donors who have a lower risk of TTIs compared to replacement donors and commercial donors in order to achieve a safe and

DOI: http://dx.doi.org/10.4314/ejhs.v28i6.4 
sufficient blood supply. About 80-100\% voluntary donations are recommended by the WHO $(5,19)$. This finding indicates that the level of volunteer donation at Dire Dawa Blood Bank is lesser compared to the WHO recommendation and the finding of other studies in Ethiopia $(20,21)$ and Africa $(18,22)$. Among the volunteer donors in this study, students comprise the greatest proportion $(55.97 \%)$. This indicates that students participate more frequently in volunteer donation campaigns.

Presence of low proportion of voluntary blood donors in this study probably reflects a basic lack of awareness and health education in the general population. The other reasons might be the presence of misconceptions and fears associated with donating blood. Special programs must be organized to expand volunteer donation in order to provide a safe blood to meet clinical demand. Therefore, much work remains to be undertaken to develop the highest level in motivating and recruiting volunteers, nonremunerated donors; creating awareness, and standardization of the quality of service in the region.

The male predominance in blood donation in this study may be explained by the fact that there is a general belief that men are healthier than women, and thus are more suitable for blood donation $(23,24)$. It can be also explained in part by some physiological status of women like menstruation, pregnancy and breast feeding, which prohibited the females from the blood donation temporarily (19).

In this study, the age groups of 18 to 24 years and 25 to 32 years were the most represented with percentages of $38.22 \%$ and $32.23 \%$ respectively. This indicates that the youth are the main blood donors. This might be explained by the fact that Ethiopia as one of the developing countries, the young represent the biggest fraction of the population compared to the older age (25) and that they are also the major age groups that fulfill the selection criteria for blood donation compared to the other age groups (older age).

This study showed that $7.06 \%$ of the donated blood was seropositive for at least one of the screened markers. This magnitude is low compared to the finding of a similar study conducted in Gonder, Northwest Ethiopia, which reported a prevalence of $9.5 \%$ transfusion transmissible infections among blood donors (14). Another cross-sectional study reported from Felege Hiwot Referral Hospital, Northwest Ethiopia reported a very high prevalence $(43.2 \%)$ of blood borne infections among blood donors compared to our study (13). When compared to other studies conducted in other African countries, the prevalence of TTI in this study is high compared to Namibia, $1.3 \%,(26)$ and low compared to Tanzania, $15.9 \%$ (18).

In this study, the overall positivity rates of HBV, HIV, HCV and syphilis were $4.67 \%$, $1.24 \%, 0.96 \%$ and $0.44 \%$ respectively. The seroprevalence of HBV $(4.67 \%)$ in this study is in agreement with a previous finding from Western Ethiopia (Gonder) (4.7\%) (14) and lower than $25 \%$ in Ethiopia (13), $10.53 \%$ in Ghana (16), $7.5 \%$ in Nigeria (27), $10.1 \%$ and $6.76 \%$ in Cameroon (17) and $8.8 \%$ in Tanzania (18). However, it is higher than the $0.46 \%$ in Nepal (28), $0.87 \%$ in China (29), $1.93 \%$ in India (30), $3.91 \%$ in Pakistan (31) and 0.6\% in Namibia (26).

The overall prevalence of HIV $(1.24 \%)$ in this study is lower than the $3.8 \%, 5.9 \%$ and $13.3 \%$ in Ethiopia $(13,14,32)$. Similarly, it is lower than the $3 \%$ in Sudan (33), $4.1 \%$ in Cameroon (17), $3.09 \%$ in Gabonese (22) and 3.8\% in Tanzania (18). However, it is higher than the findings from Nepal $(0.12 \%)$ (28), China $(0.86 \%)$ (29), India $(0.14 \%)(34)$, Namibia (0.3\%) (26) and Nigeria (0.96\%) (27).

The prevalence rate of $\mathrm{HCV}$ infection in blood donors was revealed to be $0.96 \%$, which is lower than $5.63 \%$ in Ghana (16), $4.8 \%$ in Cameroon (17), 3.1\% in Sudan (33), 8.34\% in Pakistan (31), 2.78\% in Gabonese (22) and 1.5\% in Tanzania (18). However, it is higher compared to $0.7 \%$ in Ethiopia (14), $0.64 \%$ in Nepal (28), $0.31 \%$ in China (29), $0.27 \%$ in India (30) and $0.1 \%$ in Namibia (26).

The $0.44 \%$ of syphilis positive donations among donors in this study was low compared to other study findings done in other African 
countries, $1.3 \%$, in Western Ethiopia (14), 2.61\%, in Nigeria (27), 2.7\%, in Sudan (33), 4.7\% in Tanzania (18), and $5.7 \%$ in Cameroon (17). However, the prevalence was higher compared to different findings from India $(0.16 \%)(30)$.

A comparison of our result with other studies from different countries showed a variable result. This might be explained by the difference in epidemiology and transmission of TTIs in different parts of the world. Other potential factors that might contribute to the variable pattern of TTIs can be difference in population in terms of lifestyle, awareness, sensitivity, specificity of tests and donor selection criteria.

In this study, overall trend analysis for TTIs showed a significant decrease from $9.51 \%$ to $6.95 \%$ among blood donors over the study period. This trend is similar with the findings of studies conducted in Northwest Ethiopia (14). The declining trends of the seroprevalence of TTIs may be due to the changes/improvements made by the blood bank for proper selection of donors. Separately, each pathogen shows different trends. The trend for HBV shows a continuous decrease from 2010 to 2012 year, but slight increase in 2013. The trend for prevalence of syphilis decreased progressively over the study period. This finding is consistent with the observed declining trend of syphilis infections among blood donors in Gonder (14) and declining trend of syphilis infections among pregnant women in Addis Ababa (12). Similar declining trend of syphilis was reported from Bhopa (35), Nigeria (27) and Dhiraj (Piparia) (36). This decrease may be related to a positive effect of the prevention programs against HIV, as syphilis is a sexually transmitted disease.

The prevalence of TTIs was significantly higher among male donors $(7.46 \%)$ compared to female donors $(4.76 \%)$. The difference is significant for HBV infections, but not significant for HCV, HIV and syphilis infections. This might be due to some risk behaviors such as outside socialization, multiple sex relationships which frequently observed in Males. It may also be due to fewer females donating blood; hence, fewer females are screened compared to males.
Seroprevalence rates of TTIs in relation to age range distribution showed that the prevalence of TTIs increased with age. Donors with age group 18-24 $(6.20 \%)$ showed a low prevalence of TTIs. The difference is significant for HIV, in which less prevalence is observed among donors with age group 18-24(0.60\%). For HBV, HCV and syphilis infection, the prevalence rate was lowest in the same age range though it is not significant. This is in contrary to the fact that the life period of 15 to 25 years is also a period of intense sexual activity favorable to the infection transmission. This might be due to a success on the part of government agencies and nongovernmental organizations in the fight against new HIV infections in this age group.

It is known that malaria is endemic in Ethiopia (37). However, most of the blood banks in Ethiopia do not screen blood donors for malaria. Similarly, blood donors were not screened for malaria at the Dire Dawa blood bank during the time of the study. They screened malaria only by assessing the donors for the past history of malaria infection. Therefore, testing donors for malaria should be initiated and promoted on the site for the development of transfusion services.

This study had some limitations. It collected information from secondary data which cannot be assessed for different factors that are epidemiologically important. A single positive test was considered positive for the purpose of this study. There was no confirmatory test performed. Therefore, false positives cannot be excluded, and that the true infectious disease rates may be lower than the reported.

In conclusion, this study has shown that a significant percentage of the blood donors harbor TTIs. Although the prevalence of TTIs in the study area shows a decreasing trend, the observed prevalence at each year are still high. The decreasing trends of sero-prevalence of HBV, $\mathrm{HCV}$, HIV and syphilis prevalence in blood donors did not mean safe blood supply. Hence, stringent donor selection, strict pre-screening using standard methods, subsequent follow-up for TTIs after blood transfusion and preventive measures to control infections in the general 
population are highly recommended to ensure the safety of blood for recipient. Blood safety remains an issue of major concern in this study area where replacement donors are predominant. Efforts on motivating, educating and creating awareness in the community should be made to increase the proportions of voluntary donors.

\section{ACKNOWLEDGEMENTS}

The authors greatly acknowledge Dire Dawa Health Bureau, the Blood Bank of Dire Dawa and the Department of Medical Laboratory Sciences, Haramaya University, for their endless facilitation of the Project and provision of all necessary materials. We wish to extend our deep appreciation to all staffs of Dire Dawa Blood Bank for their technical support.

\section{REFERENCES}

1. Bihl F, Castelli D, Marincola F, Dodd RY, Brander C. Transfusion-transmitted infections. J Transl Med. 2007;5(25):1-11.

2. Bloch EM, Vermeulen M, Murphy E. Blood transfusion safety in Africa: a literature review of infectious disease and organizational challenges. Transfus Med Rev. 2012;26(2):164-80.

3. Kaur P, Basu S. Transfusion-transmitted infections: existing and emerging pathogens. J Postgrad Med. 2005;51(2):146.

4. Kitchen AD, Barbara JA. Transfusiontransmitted Infections. Practical Transfusion Medicine, Second Edition. 2001:208-28.

5. World Health Organization. Status of Blood Safety in the WHO African Region: Report of the 2010 Survey.

6. World Health Organization. Sexually Transmitted Infections (STIs). The importance of a renewed commitment to STI prevention and control in achieving global sexual and reproductive health. Geneva: WHO; 2013.

7. De Schryver A, Meheus A. Epidemiology of sexually transmitted diseases: the global picture. Bulletin of the World Health Organization. 1990;68(5):639.

8. Lewis DA. HIV/sexually transmitted infection epidemiology, management and control in the IUSTI Africa region: focus on sub-Saharan Africa. Sex Transm Infect. 2011;87(Suppl 2):10-13.

9. Aseffa A. Viral diseases in Ethiopia: a review. East Afr Med J. 1993;70(10):624-6.

10. Ayele AG, Gebre-Selassie S. Prevalence and risk factors of hepatitis B and hepatitis C virus infections among patients with chronic liver diseases in public hospitals in Addis Ababa, Ethiopia. ISRN Trop Med.2013.

11. Kahsay AG DF, Kelbore AG, Getachew S. Prevalence and Associated Factors of Sexually Transmitted Infections Based on the Syndromic Approach among HIV Patients in ART Clinic; Ayder Referral Hospital, Northern Ethiopia. Clin Med Res. 2015;4(5):132-8.

12. Tsegaye A, De Wit TR, Mekonnen Y, Beyene A, Aklilu M, Messele T, et al. Decline in prevalence of HIV-1 infection and syphilis among young women attending antenatal care clinics in Addis Ababa, Ethiopia: results from sentinel surveillance, 1995-2001. J Acquir Immune Def Syndr. 2002;30(3):359-62.

13. Dessie A, Abera B, Wale F. Seroprevalence of major blood-borne infections among blood donars at Felege Hiwot referral hospital, Northwest Ethiopia. Ethiop $J$ Health Dev. 2007;21(1):68-9.

14. Tessema B, Yismaw G, Kassu A, Amsalu A, Mulu A, Emmrich F, et al. Seroprevalence of HIV, HBV, HCV and syphilis infections among blood donors at Gondar University Teaching Hospital, Northwest Ethiopia: declining trends over a period of five years. BMC Infect Dis. 2010;10(111):1.

15. CSA. Central Statistical Authority report of Ethiopia. Addis Ababa, Ethiopia. 2008.

16. Nkrumah B, Owusu M, Averu P. Hepatitis B and $\mathrm{C}$ viral infections among blood donors. $\mathrm{A}$ retrospective study from a rural community of Ghana. BMC Res Note. 2011;4(1):529. 
17. Noubiap JJN, Joko WYA, Nansseu JRN, Tene UGl, Siaka C. Sero-epidemiology of human immunodeficiency virus, hepatitis B and $\mathrm{C}$ viruses, and syphilis infections among first-time blood donors in Edea, Cameroon. Int J Infect Dis. 2013;17(10):832-837.

18. Matee MI, Magesa PM, Lyamuya EF. Seroprevalence of human immunodeficiency virus, hepatitis $\mathrm{B}$ and $\mathrm{C}$ viruses and syphilis infections among blood donors at the Muhimbili National Hospital in Dar Es Salaam, Tanzania. BMC Public Health. 2006;6(1):21.

19. Tagny CT, Owusu-Ofori S, Mbanya D, Deneys V. The blood donor in sub-Saharan Africa: a review. Transfus Med. 2010;20(1):110.

20. Birhaneselassie M. Prevalence of Transfusion-Transmissible Infections in Donors to an Ethiopian Blood Bank Between 2009 and 2013 and Donation Factors That Would Improve the Safety of the Blood Supply in Underdeveloped Countries. Lab Med. 2016;47 (2):134-9.

21. Kebede W, Mekonnen Z, Gerbi A, Abebe G. Transfusion-transmissible infection surveillance among blood donors in Southwest Ethiopia: A six years retrospective study. Asian Pac J Trop Dis. 2017;7(3):15661.

22. Rerambiah LK, Rerambiah LE, Bengone C, Siawaya JD. The risk of transfusiontransmitted viral infections at the Gabonese National Blood Transfusion Centre. Blood Transfus. 2014;12(3):330-3.

23. Bani M, Giussani B. Gender differences in giving blood: a review of the literature. Blood Transfus. 2010;8(4):278-87.

24. Bala SS, Handoo S, Jallu AS. Gender Differences in Blood Donation among Donors of Kashmir Valley. IOSR J Dent Med Sci. 2015;14(2):116-9.

25. CSA I. Ethiopia demographic and health survey 2011. Addis Ababa, Ethiopia and Calverton, Maryland, USA: Central Statistical Agency and ICF International.

26. Mavenyengwa RT, Mukesi M, Chipare I, Shoombe E. Prevalence of human immunodeficiency virus, syphilis, hepatitis B and $\mathrm{C}$ in blood donations in Namibia. $B M C$ Public Health. 2014;14(1):424.

27. Salawu L, Bolarinwa R, Adegunloye A, Muraina H. HBsAg, anti-HCV, anti-HIV and VDRL in blood donors: Prevalence and trends in the last three and a half years in a tertiary health care facility in Ile-Ife, Nigeria. Int $J$ Med Med Sci. 2010;2(11):335-41.

28. Shrestha AC, Ghimire P, Tiwari BR, Rajkarnikar M. Transfusion-transmissible infections among blood donors in Kathmandu, Nepal. J Infect in Developing Countries. 2009;3(10):794-7.

29. Song Y, Bian Y, Petzold M, Ung COL. Prevalence and trend of major transfusiontransmissible infections among blood donors in Western China, 2005 through 2010. PloS one. 2014;9(4).

30. Chaudhary V, Agrawal VK, Sexena SK, Upadhyay D, Singh A, Singh SP. Seroprevalence of common transfusion transmissible infections among blood donors in western Uttar Pradesh, India. Int J Med Sci Public Health. 2014;3(11):1381-4.

31. Waheed U, Khan H, Satti H. Prevalence of transfusion transmitted infections among blood donors of a teaching hospital in Islamabad. Ann Pak Inst Med Sci. 2012;8(4):236-9.

32. Sentjens R, Sisay Y, Vrielink H, Kebede D, Ader H, Leckie G, et al. Prevalence of and risk factors for HIV infection in blood donors and various population subgroups in Ethiopia. Epidemiol Infect. 2002; 128(02):221-8.

33. Abdallah TM, Ali A. Sero-prevalence of transfusion-transmissible infectious diseases among blood donors in Kassala, eastern Sudan. J Med Med Sci. 2012;3(4):260-2.

34. Sabharwal ER, Biswas NK, Purohit V. Prevalence and patterns of transfusion transmissible infections among blood donors in Sri Ganganagar, Rajasthan, India:-A retrospective study. J Pharm Biomed Sci. 2012;15(15).

35. Sawke N, Sawke G, Chawla S. Seroprevalence of common transfusion- 
transmitted infections among blood donors. People's J Sci Res. 2010;30(1):5-7.

36. Jasani J, Patel V, Bhuva K, Vachhani A, Patel H, Falleiro JJJ. Sero-prevalence of transfusion transmissible infections among blood donors in a tertiary care hospital. Int J Biol Med Res. 2012;3(1):1423-5.
37. Alelign A, Dejene T. Current Status of Malaria in Ethiopia: Evaluation of the Burden, Factors for Transmission and Prevention Methods. Acta Parasitol Globalis. 2016;7(1):1-6.

DOI: http://dx.doi.org/10.4314/ejhs.v28i6.4 